\title{
The Effect of Training and Informational Technology Management on Organizational Performance of Sharjah Police
}

\author{
Abdullah Awadh \\ Management Science University, Malaysia \\ Sharjah Police, Sharjah, United Arab Emirates \\ E-mail: Abdulla.awadh.a@gmail.com \\ Hassan Al-Dhaafri \\ Assistant Professor, University of Dubai \\ Dubai Police, Dubai, United Arab Emirates \\ E-mail: Hassan_Saleh3@hotmail.com
}

Received: April 2, 2018 Accepted: May 10, $2018 \quad$ Published: July 1, 2018

doi:10.5296/jmr.v10i3.13104

URL: https://doi.org/10.5296/jmr.v10i3.13104

\begin{abstract}
The main purpose of this study is to investigate the effects of Training and Information Technology (IT) Management on Organizational Performance. Based on a theoretical foundation and a wide review of the literature, the model of the research was proposed. To achieve the research purpose, this study has integrated different theories such as Resource Based View of the Firm (RBV), Knowledge Based View (KBV) in order to analyze the effect of Training and IT Management on Organizational Performance. 341 Questionnaires were distributed among random selected sample of Sharjah Police departments in Sharjah city in Emirates. 245 questionnaires were returned and used in the analysis using the SPSS system. The results of this study demonstrate that including Information Technology (IT) Management has positive and significant effect on Organizational Performance in Sharjah Police. This study reflects the importance of the right implementation to the Training and IT Management to have successful performance. This study also supported the premises of the resource-based view theory by reaffirming the importance of the including Training and IT Management to enhance organizational performance.
\end{abstract}

Keywords: training, performance, Sharjah Police, information technology. 


\section{Introduction}

The Sharjah police was initially set up as the General Security Police force, up until 1967. In this regard, the late H.H. Sheikh Khalid Bin Mohammed Al Qasimi issued the decree for its establishment; first, the force was initially established as a local department that had affiliations with the Sharjah ruler and it was under the police station and general security chief's supervision, which both committed Sharjah's qualified citizen, Colonel Abdullah Juma Al-Saree, and Mr. Burner from Oman British Coast as the supervisors and trainers of

the force, with the assistance of Mr. Abdullah Juma Al-Saree. By 1971, the UAE the Ministry of Interior was set up as the new federal system during which H.H. Sheikh Dr. Sultan Bin Mohammed Al-Qasimi, a Federal Supreme Council member, and Sharjah ruler passed a decree to integrate the general security and police departments of the city of Sharjah to the Ministry of Interior. In the present time, the General Directorate of Sharjah Police comprises numerous departments in various security and police fields and referred units along with the east region police directorate (Korfakhan, Kalba, Diba Al Hisn) in the Emirate's east coast.

On the basis of what was submitted by the Sharjah Police, the Cabinet decided to approve decision No. (3) in 1995 to enhance Sharjah Police to become a general directorate and include nine departments. By 1996, the Sharjah Police was rearranged and became known ad Sharjah Police Headquarters based on the ministerial decision No. (298) and this culminated in the qualitative transformation of the police organization, duties and style of work to a more modernized manner to keep abreast with the current changes and to assume the burdens of sustaining security and safety that the emirate was used to since its establishment. The police are free to leverage latest methodologies in undertaking their responsibilities of fighting modern crime styles that have become widespread.

\section{Related Literature Review}

\subsection{Organizational Performance}

Research on organization and the field of humanity primarily concentrated on organizational performance owing to its importance in developing organizations, their competitiveness and their effectiveness.For instance, Combs, Crook, Shook, David and Ketchen (2005) noted that organizational performance in management literature is one of the main variables that studies of organizations and strategic management have focused on. Also, practitioners and academics have brought forward several studies concerning organizational performance to shed light into the processes and antecedents and to enhance the outcomes of organizations (Jing \& Avery, 2008).

In addition, in Lloyd and Modlin's (2012) study, job performance was considered as employee behaviors that contribute to the achievement of organizational objectives and they are categorized into efficiency, productivity and effectiveness. In particular, efficiency was employed to evaluate employees' job performance, productivity was employed to compute efficiency cost and effectiveness was employed to represent the value of efficiency and productivity. 
Despite the number of studies, the findings remain inconsistent. For instance, Chambel and Castanheira (2007) reported a significant zero-order correlation between performance and status, indicating greater performance among temps compared to permanent employees, whereas in Kinnuen, Makikangas, Mauno, Siponen and Natti (2011), a greater self-rated job performance was found for permanent workers compared to temporary workers.

Moreover, only a few organizations posses formal processes to tackle managerial succession (Hart, 1991); for instance, the National Association of Corporate Directors reported in 2008 that $42 \%$ of companies surveyed did not generate CEO succession plan (Davis \&Nosal, 2009).

Aside from decreased organizational performance, transition of management has also been reported to maximize the survival of organizations (Carroll, 1984; Haveman, 1993; Haveman\&Khaire, 2004), breach the strategy of the organization (Virany et al., 1992; Wiersema, 1992), and breach the interpersonal relationships within the organization (Grusky, 1963).

In a related study, O'Toole and Meier (2003) reported negative effects of the time spent by the new commander in networking on organizational performance, specifically in the short-term performance. In this regard, an interview guide is provided to create the required structure for the COMTRAIN process of transition.

\subsubsection{Organizational Performance Definition}

Organizational performance system abounds with complex facets that consist of six different performance conditions, which are efficiency, effectiveness, innovation, quality, productivity and profitability (Sink \& Tuttle, 1989).

Organizational performance is described as the measure of the organization's ability to manage and deliver value to stakeholders, including customers (Moullin, 2007). Antony and Bhattacharyya (2010) referred to it as a tool and measure employed to assess and evaluate the successful creation and delivery of the organization of customer (internal and external) value.

In the present dynamic business environment, measurement of organizational performance is extensively emphasized owing to its importance in evaluating the success rate of the strategy that the organization uses (Neely, 1999) as without such measurement, it is impossible to know whether or not it improved and how to improve it.

\subsubsection{Measuring Organizational Performance}

It is crucial to measure performance in order to achieve effective organizational management (Demirbag, Tatoglu, Tekinkus \& Zaim, 2006). Performance measurement is thus an important component of management (Pongatichat\& Johnston, 2008) and it plays a key role in communication and in promoting the awareness of the employees in this regard to improve the performance of the organization as a whole (Kanji \& Sa, 2006).

Its main aim is to confirm developments towards the core objective, which is to determine enhancement opportunities, achieve the alignment of the organization with the goals, enhance 
accountability, direct future allocation of resources, and convince employees to contribute to strategy and display contributing attitudes and behaviors (Kanji \& Sa, 2006). There are four performance measurement areas that have to be considered and they are; achieving process excellence, maximizing value of stakeholders, satisfying and delighting customers and improving learning in the organization.

According to Deming (1986), a thing cannot be improved without measuring it and this applies to organizational performance in that it needs suitable measurements to determine the effectiveness level of the resources in running the business (Gadenne\& Sharma, 2002; Madu, Kuei\& Jacob, 1996).

More importantly, organizational performance has been traditionally measured using financial measurement indicators that are full of weaknesses and to address such weaknesses, some researchers use both financial and non-financial indicators (Demirbag, Koh, Tatoglu \& Zaim, 2006).

Studies of this caliber (e.g., Dawkins, Feeny \& Harris, 2007; Debnath \& Shankar, 2008) explained that benchmarking is a tool that enhances organizational performance. Based on the above, organizations that fail to practice benchmarking as a main process of performance measurement will realize little to no improvement, highly dissatisfied employees and high turnover.

In a related study, Neely, Gregory and Platts (2005) referred to performance measurement as a group of metrics used in quantifying effective and efficiency actions. These metrics can facilitate the process of decision making by collecting, overseeing and analyzing information related to performance (Garengo \& Bititci, 2007). This type of information helps in developing effective activities of the organization that pertains to planning, management, control and performance.

Traditional performance measurement, as discussed, is primarily based on financial measurement indicators including profit, debt, sales, turnover and return on investment and these are insufficient indicators in the present dynamic business environment. This highlights the need to use non-financial measures as supported by prior studies (Johnson, 1983; Kaplan, 1984) that reported insufficient effectiveness of such measures in measuring performance. In relation to the above, profit both a financial measure and is a crucial business driver, but despite this fact, it falls short of depicting the ability and capability of the firm to generate profits (Burns, 1998).

In contrast, non-financial performance indicators like the development of stakeholders (employees, society and customers) value has to be on the forefront as they are the predictors of financial performance (Kristensen \& Westlund, 2004).

According to Kristensen and Weslund (2004), the successful implementation of financial and non-financial performance is referred to as the organization or business excellence. To conclude, the present dynamic business environment needs to lay greater emphasis on the non-financial performance indicators and measurements. 


\section{Training}

Generally, the role of training in the Middle East region, massive amounts of oil reserves has allowed the countries to investment in the region's infrastructure (Nuserait et al., 2014). Private organizations all over the globe were attracted in investing in the region and to make sure that public and private organizations meet the increasing business influx, the financial reserves were utilized to obtain the best practices in management. These were then used for the maintenance of the increased rate of development. Zoubi (1982) revealed this period in the $80 \mathrm{~s}$ as the decade of administrative development (cited in Nuserait et al., 2014).

In any organization, the knowledge and skills of the employees are increasing in importance in terms of performance competitiveness.

The crucial role of HRM in contributing to the firm competitiveness has been hailed by scholars and practitioners in the past years, largely overlooking the importance of workplace learning and ongoing improvement in light of the same (Salas \& Cannon-Bowers, 2001). In relation to this, successful organizations tend to invest in training and development (Kraiger, 2003) more than their less-successful counterparts. Also, human resources have become a significant source of competitive advantage in the present world that is experiencing a shift towards a knowledge-based economy (Pena \& Villasalero, 2010), and these arguments hold true in the service sector.

In this study, professional training is viewed as formal learning and support activities and initiatives created for the organizations to leverage opportunity of preparation and development of human resource. Such opportunities often lead to improved knowledge, skills, practices and dispositions of workers when successfully transferred. Training transfer refers to process, where knowledge, skills, and practices learned during the training are practically manifested by workers (Russ-Eft et al., 2010).

Training is defined as the systematic creation of knowledge, skills and attitudes provided to the individual for task completion and it is the planned process of changing attitude, knowledge or skill behavior through learning to perform a task (Glossary of Training Terms, Manpower Services Commission, U.K.). In the workplace situation, training is geared towards developing the individual's abilities and satisfying the organization's needs in terms of manpower requirements for the present or future. In other words, training leads to improved overall performance, with performance being related to training. In other related studies, training is referred to as the expansiveness of formalized initiatives used to develop knowledge, skills and abilities (Evans \& Davis, 2005, p.760) that is provided to human resource to enhance their performance on the job (Guzzo, 1988).

\subsection{Objectives of Training}

After determining the needs of training, the objective behind it has to be designed and established. Such aim is related to the training needs and this may be provided in a summarized or extensive way (e.g., an advertisement). 
In the initial step, an objective is used to link what learners' capabilities after training, after achieving a standard performance under the training conditions. This is known as the training objective and it is established prior to the training program. Objectives are generally covered under different topics;

- After training, the trainees are expected to be capable of providing an explanation of the concept of precursor control and descriptions of the control requirements as a strategy to cover the illegal drugs supply.

- After training, trainees are expected to be capable of describing licit or illicit uses of precursors (see Tables I and II of U.N. Convention, 1988).

- After training, trainees are expected to be capable of examining suspect substances through the use of precursor identification field test kit and decide whether it is a precursor chemical.

- After training, trainees are expected to be capable of determining and preventing diversion cases of precursor chemicals for illicit use purposes.

A systematic training method calls for designing the training initiative as training has to be designed through the cooperation of the workers at various levels and if required, consultants are hired. The training program design has to be customized to satisfy individual and group objectives.

Several purposes are served by precursor control training programs and they include the provision of knowledge, enhancement of technical skills and facilitating changes in attitudes. Emphasis on a particular aim may vary from one program to another, according to the factors such as, the type of audience, the level of participants, among others.

\subsection{Key Strategies of Training}

The Key Strategies Rating Questionnaire (KSRQ) refers to a measurement that gauges the acquisition of individuals of intermediate psychotherapy intervention strategies as explained by Kelley (2011). In the case of spatial strategy applications, Workman and Lee (2004) looked into the existence or lack thereof of changes and cultural differences in the changes in the spatial and professional abilities prior and following lessons/classes of apparel design. They carried out retrospective interviews and requested the participants to remember the strategies used when providing answers to the questions.

This marks the increasing need for effective training programs in organizations all over the globe - in both public and private firms. This adds to the necessity of police organizations to look after its police officers as they maintain the societal welfare, and to prevent releasing them into the field sans sufficient skills to react and address situations in a timely manner. Their lack of skills can result in increased crime rates and lose the public's trust on the police force. Indubitably, this lack of trust will lead to specific levels of societal lawlessness and thus, it is crucial for police officers to be trained for skills and knowledge acquisition on the procedures involved in a crime in order so that they may effectively respond to them. 
Over the past years, several organizations have acknowledged employees as a significant resource and this has transformed the scientific management of HR to a more behavioral, employee-centered management. Managers are now convinced that money may not be sufficient incentive for employees to ensure successful long-term organizational processes.

This is more apparent presently than ever before with the businesses investing more and more to make sure that their employees and company are aligned in their goals by providing the former with training and development. Such development requires continuous efforts so that the organization keeps abreast of the ever-evolving needs in the market through the effective employees handling of issues through training (Ho \& Yeung, 2015).

In the same line of study, Lemaire and Lecacheur (2010) examined the use of varying arithmetic strategies over trials involving instructions to switch and voluntary switching. In the two cases, participants indicated their preference for switching strategies between trials, and upon doing so, performance dipped, especially with the simpler tasks and strategies. Also, Xetal (2009) revealed that participants who were provided an opportunity to choose strategies were more inclined to using the same strategy in two consecutive problems as opposed to using a range of strategies.

\subsection{Simulation-Based Training (SBT)}

Simulation-based training facilitates realistic, flexible surroundings within which individuals can learn new information and use such learning to simulated tasks with the aim of mastering complex material (Menaker, Coleman, Collins \& Murawski, 2006). Based on studies in literature, SBT functions as a productive alternative to textbook/classroom learning (Tichon, 2007) as it assists learners in creating and maintain new information mental modes (Cuevas, Fiore, Bowers \& Salas, 2004). As a consequence, SBT has been known to be employed in various fields/domains such as the practical military applications (e.g., Chang, 2009; Pine, 2009; Waldman, 2009). Owing to the benefits it provides, it is important for studies to look into ways to suitably integrate instructional interventions to optimize system training and cost-effectiveness.

For instance, a more memory-based problem solving strategy can assist exploratory learning (Sweller, 1988; Sweller \& Levine, 1982) and in the development of transference of various same task variations (Vollmeyer, Burns \& Holyoak, 1996). Added to this, a memory-based strategy can minimize the interruption effect when copying (Morgan et al., 2009) and when solving problems (Morgan \& Patrick, 2013), enhancing interruption lag use and enhancing the efficiency of problem solving (Morgan et al., 2013).

\subsection{Teamwork Training and Types of Training}

Teamwork training can lead to enhanced teams, with majority of studies revealing positive impacts of teamwork intervention on effectiveness via different contexts (healthcare, academia, etc.). Moreover, teamwork enhancements have been noted stemming from training of various types of teams (new teams, intact teams, laboratory-based teams). In other words, empirical evidence shows that teams can be enhanced through teamwork training. Teamwork has been conceptualized by studies into theoretical models; for instance, Rousseau et al. 
found 29 frameworks in publications that are linked to teamwork and regardless of the overlap throughout the models, there are also differences among them. These also associate with the several teamwork dimensions being conceptualized and the particular labeling of the dimensions. One of the consensus among scholars is that teamwork consists of several behaviors that can be observed and measured. In this regard, Thomas (2000) revealed that timely improvements in performance can be achieved through the use of short-term management approaches for effective training initiatives.

Team training is used to train people to solve problems, observe and provide feedback in groups during training sessions (Rasmussen, 1982; Forbush \& Morgan, 2004). It is frequently utilized in the industrial sector, government and the military (Tannenbaum \& Yukl, 1992). Certain team training strategies have been created including cross-training, coordination training (Prince \& Salas, 1993), leadership training (Tannenbaum et al., 1998), self-correction (Smith-Jentsch et al, 1998; and distributed team training (Dwyer et al., 1999). On the basis of evidence in literature, team training is effective when it is driven by theory and it focuses on the required skills providing actual opportunities for feedback to trainees (Salas \& Cannon-Bowers, 2001).

Training comprises of various strength training types directed towards developing athleticism, like sprinting and jumping and they include heavy strength/hypertrophic training, plyometric training and explosive weight/power training. These training methods employ different loads in different power-velocity curve parts. More specifically, heavy strength training generally leads to increased force production and muscle mass (Chelly et al., 2009; Cormie et al., 2010; Hakkinen, 1989; Sale, 1988; Tesch, 1989; Wilson et al., 1993), whereas plyometric training leads to increased rapid force generation (Impellizzeri et al., 2008; Matavulj et al., 2001; Markovic et al., 2007).

Lastly, explosive training is a combination of the above mentioned methods and it leads to the development of the neuromuscular performance as explained by prior literature (e.g., Cormie et al., 2010; Harris et al., 2008; Lamas et al., 2012; McBride et al., 2002; Winchester et al., 2008).

Development is defined as the planned and purposive learning in a time period in order to boost the performance on the job (Katkalo et al., 2010) and the application of theories and methods of behavioral science to improve the value of the firm resource. According to Murphy (2013), planned learning that could lead to enhanced employees' production and positive development could be referred to as on-job training and it encompasses education, training and development.

\subsection{Supervisors-in-training}

For the in-training supervisors, a mental health training program used a curriculum of theory, assessment and helping skills (Hackney \& Cormier, 2013; Hill, 2009), where the supervisors are more likely to be offered a curricular offering.

In Dubai, successful training initiatives according to Nuseriat et al. (2014) have transformed the total organizational performance of the emirate. Successful implementation of training 
programs has led to a positive view for organizations. However, on the whole, training programs have fallen short of being successful in their aims in developing countries and this was related to the theoretical focus, overlooking its use in practice. The employees' needs and the objectives of the programs were largely overlooked. This was supported by Healy (2001) who related minimal coordination among various organizational elements and training initiatives that were not obtained from prior knowledge and hence, making them ineffective in making a true change.

\subsection{Relationship between Training and Organizational Performance}

This study conducted a thorough literature review to develop and propose hypotheses about the relationship between training, IT Management and organizational performance. Two independent variables, one dependent variable. In other words, organizational performance can be improved through the adoption of good strategy that is associated with training and IT management. In many previous studies, training has a positive and significant effect on organizational performance.

The study's proposed framework concerning the effects of training and IT management on organizational performance is depicted in Figure 1. The study develops and proposes the following hypotheses:

H1: Training has a positive and significant effect on organizational performance.

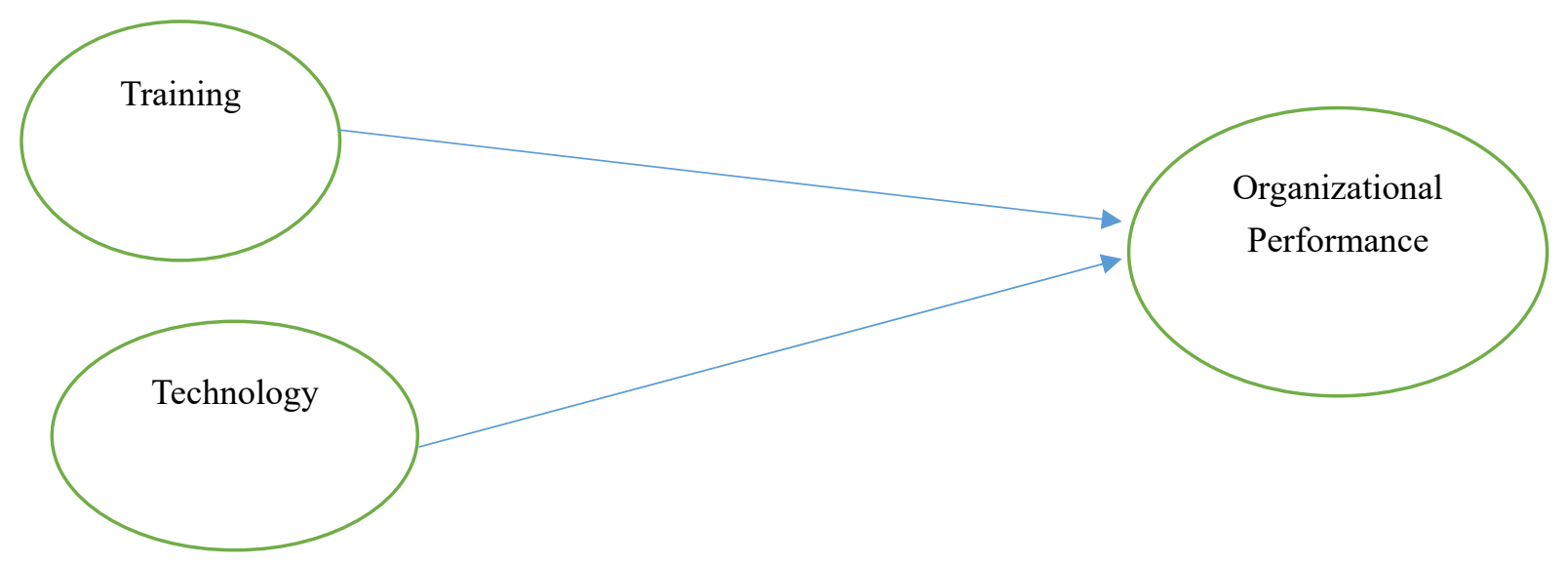

Figure 1. Research Framework

\section{Information Technology Management}

The Network of Schools of Public Policy, Affairs and Administration (NASPAA) mandated that all graduate programs in public management should include training in information systems in 1988. This was done with the aim that the shift towards mission and outcome based accreditation regime should not minimize the significance of IT training in the curricula of public administration. The IT impact on government is over encompassing and it 
needs managers to work in the IS processes, preferences, rules and assumptions (Dawes, 2004, p.6).

The IS systems pace of change called for organizations to change their structure and to consistently adapt to the new environment (Berce, Lanfranco \& Vehovar, 2008).

Based on Matei and Savulescu's (2014) argument, majority of public administration innovations have ICT components that is important to providing service to the public and to implement policies.

Along the same line of study, Kernaghan and Gunraj (2004) related that the use of IT among public firms exposes them to certain changes and they are; hiring employees with specialized skills and investing in IT infrastructure, improving efficiency through streamlined information management, and sharing and disseminating information. These predispositions can result in changes depending on the political, structural, managerial and cultural factors, moving departments and agencies towards collaboration (from departmental to no departmental forms and from hierarchy and central control to decentralization) that would lead to mitigated middle management layers in the firm.

In this regard, technological invariant is the sustained increase in the capability of handling the complexity using modular layers of technology in a platform of standardized software (Dhar \& Sundararajan, 2007). It is important for public managers to comprehend how such capability allows organizational models (that would become obsolete otherwise) and generates capabilities that were previously lacking.

Learning involving IT in e-learning enhances and supports education and learning and offers various learning strategies and applications for information exchange and skills acquisition (Candice, Sandra \& John, 1998; Sife, Lwonga \& Sanga, 2007).

Among the training types, e-learning is generally not as costly, and it is a self-paced learning, with consistent content that can be access anywhere at any time, easily updateable, managed and controlled even when providing to a significant number of people - it can help organizations to improve their performance (Cantoni, Cellario \& Ports, 2004). In fact, numerous academic an corporate training institutions around the globe are currently using e-learning and learning management systems (LMS) to improve their training strategies and methods through the introduction of virtual and mobile learning surroundings (Kumar \& Suneja, 2011).

Moreover, MLS entails the combination of several processes and materials including participant administration, lessons, courses, curriculum and file management, certifications and report buildings, recovery solutions, examinations, quizzes, and assignment design, evaluation, communication tools, progress monitoring and reports, authentication and methods of enrollment, extension modules, payment integration, tools of social network, and systems for email notification (Kuman \&Suneja, 2011). Ninety-one percent (91\%) of the surveyed firms had learning management systems (American Society for Training and Development, 2009). 
There is lack of a clear definition of technology integration in education as mentioned by Hew and Brush (2007) in their study, where they highlighted three perspectives operational in prior studies and they are; relating to the ways in which new ICT can be used by the teaching in school activities, relating to efficiency and quality assurance of the activities and relating to the development of pupil's skills.

In the context of the public sector, widespread technology innovations are encouraging managers to achieve competence in using and managing information technologies. The public service context has also been increasingly changed through the advancement of technology. In relation to this, Bowman, West and Beck (2014) revealed that IT, new media and cyber-security issues have modified the works of public services and have led to novel technical and ethical issues for the management of the public.

Despite the emphasis of teaching IT and MPA programs by NASPAA that has led to the to the incorporation of IT training into the curricula, the public sector still lacks a conceptual comprehension of what IT competence actually mean for general managers and IT managers. Prior literature indicated the need for both core technical and management knowledge (e.g., Rocheleau, 1998), strategic information resource planning (Brown \& Brudney, 1998), the importance of skills in network operations (Kim \& Layne, 2001)

\subsection{Competence and IT Competence and IT Competence for Public IT Managers}

According to McClelland (1973), the concept of competence first surfaced in the 1970 to describe an individual's specific skills sets or qualities that can be utilized by the psychology field as optimum job-performance indicators rather than standard intelligence tests. The recent stress on competence heralded the theoretical combination between academic fields of moral philosophy and management development (Macaulay \& Lawton, 2006). The result of which is the application of occupational competence following the requirement of the U.S. State Department for Certificates of Competence under the Foreign Service Act, 1980. At present, majority of public agencies have developed job-specific competencies to provide guidance, training, hiring and evaluation of the performance of employees. Such competence possess an ethical element that reflects that upholds the qualities of virtue and morality as explained in prior studies (e.g., Bowman, West \& Beck, 2014; Virtanen, 2000).

In this background, in the organization, a manager, who is competent, leverages the capabilities of technology to deliver outstanding outcomes of business (Smith, 1996, p.39), where explicit knowledge covers system development methods and practices, IT management, and knowledge access.

Tacit knowledge comprises of experience (particularly of IT project and management) and cognition (particularly of process view of organizational activities and IT vision) (Basselier et al., 2001). It is pertinent that explicit and tacit IT knowledge be combined with the working knowledge of management regarding agency goals, main strategies, priorities, threats and challenges, in order to sustain a clear perspective during the development and formation of IT solutions. 
IT managers, unlike their general public counterparts hold IT knowledge, skills and attributes as their core competence. However, this does not mean that there are basic distinctions in IT competence between their duties. In some cases, management rotation at the senior level in various functional departments exist; for instance, in the Seoul city government of South Korea, all chief department managers shift to a different department and this includes the IT department, after every two years. These enable managers to think of organizations akin to a set of processes as opposed to mere functional silos, and to comprehend the IT's power of transformation (Bassllier et al., 2001; Layne \& Lee, 2001).

It is notable that the top significant differences in competence between public IT managers and general public managers can be viewed from the individual level. Owing to the essentiality of technology in IT managers' routine work responsibilities, they are expected to go beyond technical bases and to have professional level of IT knowledge (IT infrastructure, architecture, system security, application development, among others) (Dawes, 2008), while at the same time having knowledge of present and potential technologies and applications their fields.

Viewed from this viewpoint, teaching strategies can be reflected in the following definitions; a combination of shapes, methods, technical means and their principle uses, whose assistance aim to achieve specific objectives (Chis, 1992, p.9) - it is the combination of means utilized to get the planned objective, beginning from the material organization and choice, and culminating in learning task and the needed identification of conditions.

\subsection{Advantage and Disadvantage of Technology}

Skinner (1984) presented the importance, advantages and disadvantages of computer assisted instruction and related that in the American education system, students learn twice more at the same time, with the same effort, if they use computer technology in learning.

In a related study, Papert (1972) expected the movement between intellectual development stages through timelier passing of pupils from strict operations of thinking to formal ones in proposition owing to the use of computers in education. Similarly, Feuerzeig indicated that the computer use in school learning results in developing the students' cognitive abilities and particularities as follows;

- An optimum thinking discipline, accurate mental operations and their expression, better explanation of sentences that are similar to the algorithmic computer language;

- Early development of general concepts including, formal proceeding, variable, transforming function, hypothetical-deductive rationale (programming terms);

- Employing heuristic strategies in problem solving from any area.

Also, in Gage and Berliner's (1992) study, they provided a list of advantages that computer assisted teaching can provide and they are; data storage of individual/group outcomes that are re-actualized and statistically processed for teacher's examination throughout the lesson and towards the end, the software can offer distinct teaching support to pupils capacities. It can also store information concerning the learning speed of students, present non-verbal items in 
the form of images, diagrams, figures and simulations, and hearing in the form of spelled texts, and musical pieces, on computer screens or audio boxes.

Along with the positive aspects of computer assisted teaching, are the negative aspects and based on the critics, the main methods of such teaching are linked to the heterogeneity of methods, patchy teaching model, discontinuous teaching-assimilation process that leads to cybernetic system behavior with negative feedback. It is controlled by two reaction circles and the algorithmic thinking forms a detriment to divergent thinking, difficulty of knowledge transfer and integration, isolated pupils from social interaction. Despite these criticisms, recent connection possibilities via the Internet contradict the above disadvantages to a certain extent.

\subsection{Relationship between IT Management and Organizational Performance}

This study conducted a thorough literature review to develop and propose hypotheses about the relationship between IT management and organizational performance. Three independent variables, one dependent variable and one moderating variable were considered to assist the overall performance of the organization. In other words, organizational performance can be improved through the adoption of good strategy that is associated with training and IT management. The positive and significant effect was confirmed in many previous studies about the relationship between IT Management and organizational performance. Therefore, the following hypothesis has been postulated:

H2: IT management has a positive and significant effect on organizational performance.

\section{Methodology}

The present paper examines the factors in terms of their effect on other factors included in the study model. The study framework indicates the measurement of the effect of Training and information Technology and their effects on organizational of the UAE / Sharjah police performance.

The Sharjah Police department comprises 5 general departments namely, General Commander, Deputy Commander in Chief, General Administration of Resources and Support Services, General Directorate of Police Operations and General Directorate of Central Operations. These departments are further branched out into 21 main departments, within which there are 86 head sections, including 255 branches. Such categories are concerned with daily tasks, and a head section officer that leads a group of employees leads each section.

In the pilot study, this study obtained a sample from the 30 sections and branches from a total of 311 sections and branches. The sampling frame was created with the help of human resource department, systems and official website of the Sharjah Police department.

The balanced scorecard (BSC) is capable of functioning as a new management system, particularly when implementing business strategy and to minimize the gap existing between strategy development and implementation (Kaplan \& Norton, 1996). IT management measurement items were adopted from prior studies by Cragg, Mills and Suraweera (2013), measured along a 5-point Likert scale ranging.Performance is the ultimate goal that all 
organizations are seeking to achieve. In this study, organizational performance was the dependent variable that is affected by two independent variables. To measure performance, measurements from previous studies were adopted and adapted. Organizational performance measurement was taken from the studies by Narver and Slater (1990) and Jaworski and Kohli (1993).

\section{Data Analysis}

Based on the data collected in Sharjah Police, the returned questionnaires were entered in SPSS program and analyzed. The following tables and results will explain the main important outcomes of this study.

Table 1 shows the descriptive analysis in this study. A descriptive analysis for data was conducted to describe the Training, IT Management and Organizational Performance (OP) from the respondents' perspective. In Table 1, the mean, standard deviation, minimum and maximum of the constructs were reported.

As tabulated in Table 1, the minimum value of all the constructs was 1.00 and the maximum value was 5.00 which represent the Likert scale used in this study. The same data showed that Training had the maximum mean value (3.927) among other with the lowest standard deviation (0.687). These results clearly indicated that head section officers highly focused and emphasized on Training in accomplishing the desired organizational goals and objectives. The lowest standard deviation value indicated that officers were not significantly different in their opinion about the importance of Training for sustainable competitive advantages.

IT Management's mean and standard deviation values were 3.420 and 1.002 respectively as the highest standard deviation. The results also emphasized on the importance of IT Management beside other practices explained above. The importance of Organizational Performance analysis also realized by respondents with mean value 3.493 and 0.885 for standard deviation.

Table 1. Descriptive Statistics of the Constructs

\begin{tabular}{lccccc}
\hline \multicolumn{1}{c}{ Construct } & $\mathrm{N}$ & Minimum & Maximum & Mean & Std. Deviation \\
\hline Training & 245 & 1 & 5 & 3.927 & 0.687 \\
IT Management & 245 & 1 & 5 & 3.420 & 1.002 \\
Organizational Performance & 245 & 1 & 5 & 3.493 & 0.885 \\
\hline
\end{tabular}

Correlation analysis is a statistical technique obtained to define the strength and direction of the linear association between two variables (Pallant, 2001). The degree of correlation measures the strength and importance of a relationship between variables. To attain this, a bivariate association was deployed. The technique calculates Pearsones correlation coefficient with significance level. Pearson correlation coefficients be able to only choose one value, which ranges from -1 to +1 . The greatness of the absolute value (ignoring the sign) 
delivers a clue of the strength of the correlation between two variables. The faultless relationship of +1 or -1 shows that the value of one variable might be defined precisely by identifying the value of other. Moreover, the correlation value "0" shows no relationship among indicated two variables. Based on statement of Cohen (1988) clarified the strength of the correlation between two variables (r) as displayed in following Table 2.

Simple explanation in the context of correlation analysis, the correlations explains the relationship between two variables if there is a significant or not. There is a strong correlation between variables and all relationships are significant at 0.01 level of significance. For example in table 2 that the value of the correlation between "Training and IT Management" is .697 which means there is $69 \%$ relationship between them at 0.01 level of significance $(\mathrm{r}=.697$, at $\mathrm{P}<0.01)$. The relationship between Organizational Performance and IT Management a was also highly correlated at 0.01 level of significance $(\mathrm{r}=.727$, at $\mathrm{P}<0.01)$. In addition, Training correlated with Organizational Performance $(\mathrm{r}=.656$, at $\mathrm{P}<0.01)$.

Table 2. Correlation of variables

\begin{tabular}{llccc}
\hline \multicolumn{1}{c}{ Construct } & Training & $\begin{array}{c}\text { IT } \\
\text { Manage } \\
\text { ment }\end{array}$ & $\begin{array}{c}\text { Organizational } \\
\text { Performance }\end{array}$ \\
\hline Training & $\begin{array}{l}\text { Pearson } \\
\text { Correlation }\end{array}$ & 1 & & \\
& Pearson & $.697^{* *}$ & 1 & \\
IT Management & Correlation & & & \\
Organizational & Pearson & $.656^{* *}$ & $.727^{* *}$ & 1 \\
Performance & Correlation & & & \\
\hline
\end{tabular}

**. Correlation is significant at the 0.01 level (2-tailed).

Multiple regressions is employed to study the correlation between one constant dependent variable and various independent variables. In general, there are a number of approaches of multiple regression analysis such as standard regression, hierarchical or sequential and stepwise regression (Pallant, 2001). Firstly, in standard multiple regressions, all the independent variables are go into the equation simultaneously (Pallant, 2001). Besides, multiple regression analysis was directed in this study to deliver the researcher with a selection of outcomes that can support him answer the research questions and test the research's hypotheses.

Table 3 showed the regression analysis between variables where the direct hypotheses were examined. The results of hypothesis 1 which investigates the effect of Training on Organizational Performance was insignificant at 0.05 level of significance $(\beta=-0.041 ; \mathrm{t}=$ $0.585 ; \mathrm{p}>0.1$ ), and therefore H1 was not supported. In addition, IT Management was found significant with Organization Performance $(\beta=0.152 ; \mathrm{t}=2.844 ; \mathrm{p}<0.01)$, at as shown in Table 3. 
Table 3. Regression Analysis of Direct Hypotheses

\begin{tabular}{ccccccc}
\hline Hypothesis & Relationship & Path & SE & T-value & P-value & Decision \\
\hline H1 & Training ------> OP & -0.041 & 0.076 & -0.547 & 0.585 & $\begin{array}{c}\text { Not } \\
\text { S2 }\end{array}$ \\
IT Management ---------> OP & 0.152 & 0.053 & 2.844 & 0.005 & Supported \\
\hline
\end{tabular}

$*: \mathrm{p}<0.05 ; * *: \mathrm{p}<0.01 ; * * *: \mathrm{p}<0.001$

\section{Discussion and Conclusion}

This study primarily aimed to examine the effect of training and information technology management on organizational performance. The preceding sections provide explanations of the relationships between the variables based on the results obtained.

On the basis of the obtained results, training was found to have an insignificant effect on organizational performance $(\beta=-0.041 ; \mathrm{t}=0.585 ; \mathrm{p}>0.1)$. This is in contrast to the results reported by past studies like Brinkerhoff (2005), Dermol and Cater (2013), Ubeda-Garcia, Marco-Lajara, Sabater-Sempere and Garcia-Lillo (2013).

On the basis of the obtained results, IT Management Effect on Organizational Performance was found to have an insignificant effect on organizational performance $(\beta=0.152 ; t=2.844$; p $>0.5$ ) in line with previous studies (e.g., Cantoni, Cellario \& Ports, 2004; Kumar \&Suneja, 2011).

On the whole, the Sharjah police department remains a top priority when it comes to the UAE development. Thus it remains important for the departments to help in achieving the goals and objectives of the country. Based on prior studies, training and IT management all have key roles as strategies used to enhancing organizational performance and facilitating competitive advantage.

Based on this study's results, the hypotheses were confirmed, and were either rejected or supported in terms of the effect of training and IT management on organizational performance.

This study managed to highlight issues concerning the police departments performance in Sharjah, UAE. This study, to the best of the researcher's knowledge, is a pioneering study conducted in the Middle East that examined the joint effect of training and IT management on the performance of organizations.

Finally, the findings of the results were obtained from data collected from the head sections of the units of Sharjah Police as they are the top personnel having knowledge and experience of the impact of the study variables on the performance of their organizations. In relation to this, future studies may adopt a varying perspective by obtaining and gathering data from the customers and other employees. 


\section{References}

Altinay, L., \& Altinay, E. (2006). Determinants of ethnic minority entrepreneurial growth in the catering sector. The Service Industries Journal, 26(2), 203-221. https://doi.org/10.1080/02642060500369354

Arthur, J. (1994). Effects of human resource system on manufacturing performance and turnover. Academy of Management Journal, 37, 670-687.

Antony, J. P., \& Bhattacharyya, S. (2010). Measuring organizational performance and organizational excellence of SMEs - Part 2: an empirical study on SMEs in India. Measuring Business Excellence, 14(3), 42-52. https://doi.org/10.1108/13683041011074209

Bassellier, G., Reich, B. H., \&Benbasat, I. (2001). Information technology competence of business managers: A definition and research model. Journal of Management Information Systems, 17(4), 159-182. https://doi.org/10.1080/07421222.2001.11045660

Bruns, W. (1998). Profit as a performance measure: powerful concept, insufficient measure. Performance Measurement - Theory and Practice: The First International Conference on Performance Measurement, (pp. 14-17). Cambridge, July.

Blandy, R., Dockery, M., Hawke, A., \& Webster, E. (2000). Does Training Pay? Evidence from Australian Enterprises. National Centre for Vocational Education Research.

Brown, J. (2002). Training needs assessment: A must for developing an effective training program. Public Personnel Management, 31(4), 569-578. https://doi.org/10.1177/009102600203100412

Berce, J., Lanfranco, S., \& Vehovar, V. (2008). Egovernance: Information and communication technology, knowledge management and learning organisation culture. Informatica, 32(2), 189-205.

Carroll, G. (1984). Dynamics of publisher succession in newspaper organizations. Administrative Science Quarterly, 29(1), 93-113. https://doi.org/10.2307/2393082

Campbell, J. (1971). Personnel training and development. Annual Review of Psychology, 22(1), 565-602. https://doi.org/10.1146/annurev.ps.22.020171.003025

Cuevas, H. M., Fiore, S. M., Bowers, C. A., \& Salas, E. (2004). Fostering constructive cognitive and metacognitive activity in computer-based complex task training environments. Computers in Human Behavior, 20, 225-241 https://doi.org/10.1016/j.chb.2003.10.016

Chang, H. (2009). Simulators always valuable in military training. Retrieved January 20, 2010, from http://www.army.mil/-news/2009/04/13/19599-simulators-always-valuable-in-militarytrainin g/index.html

Campbell, \& Stasser's. (2006). Mesmer-Magnus and De Church's (2009) and Mesmer-Magnus et al.’s (2011) 
Chelly et al., 2009; Cormie et al., 2010; Hakkinen, 1989; Sale, 1988; Tesch, 1989; Wilson et al., 1993), (Impellizzeri et al., 2008; Matavulj et al., 2001; Markovic et al., 2007).

Cormie et al., 2010; Harris et al., 2008; Lamas et al., 2012; McBride et al., 2002; Winchester et al., 2008).

Caudron, S. (2002). Just say no to training fads. Training and Development, 56(6), 40-43.

Combs, J., Liu, Y., Hall, A., \& Ketchen, D. (2006). Do high performance work practices matter? A meta-analysis of their effects on organizational performance. Personnel Psychology, 59, 501-528.

Demirbag, M., Koh, S. C., Tatoglu, E., \& Zaim, S. (2006). TQM and market orientation's impact on SMEs' performance. Industrial Management \& Data System, 106(8), 1206-1228. https://doi.org/10.1108/02635570610710836

Deming, W. E. (1986). Out of the crisis. Cambridge, MA: MIT Institute for Advanced Engineering Study.

Dawkins, P., Feeny, S., \& Harris, M. N. (2007). Benchmarking firm performance. Benchmarking: An International Journal, 14(6), 693-710. Demirbag, Koh, Tatoglu\&Zaim, 2006). https://doi.org/10.1108/14635770710834491

Dechawatanapaisal, D., \& Siengthai, S. (2006). The impact of cognitive dissonance on learning work behavior. Journal of Workplace Learning, 18(1), 42-54. Dwyer et al., 1999. https://doi.org/10.1108/13665620610641300

Dolezalek, H. (2005). 2005 industry re Delery, T., \& Doty, D. (1996). Modes of theorizing in strategic human resource management: test of universalistic, contingency and configurational performance predictions. Academy of Management Journal, 39(4), 802-835. port. Training, 42(12), 14-28.

Grusky, O. (1963). Managerial succession and organizational effectiveness. American Journal of Sociology, 69(1), 21-31. https://doi.org/10.1086/223507

Gadenne, D., \& Sharma, B. (2002). An inter-industry comparison of quality management practices and performance. Managing Service Quality, 12(6), 394-404. https://doi.org/10.1108/09604520210451876

Garengo, P., \&Bititci, U. (2007). Towards a contingency approach to Performance Measurement: an empirical study in Scottish SMEs. International Journal of Operations and Production Management, 27(8), 802-825. https://doi.org/10.1108/01443570710763787

Guo, W. (2011). Research on Specific On-Job Training of Enterprise and Shortage of Skilled Workers. Journal of Taishan University, 1, 021.

Guzzo, R.A., Jette, R.D., \& Katzell, R.A. (1985). The effects of psychologically based intervention programs on worker productivity: a meta-analysis. Personnel Psychology, 38, pp. 275-91. https://doi.org/10.1111/j.1744-6570.1985.tb00547.x 
Garvin, D., Edmondson, A., \& Gino, F. (2008). Is yours a learning organization?. Harvard Business Review, 51(2), 109-116.

Hart, A.W. (1991). Leader succession and socialization: a synthesis. Review of Educational Research, 61(4), p 451-74. https://doi.org/10.3102/00346543061004451

Huang, S., \& Weiler, B. (2010). A review and evaluation of China's quality assurance system for tour guiding. Journal of Susainable Tourism, 17(7), 845-860.

Hacker, D. J., Bol, L., \& Bahbahani, K. (2008). Explaining calibration accuracy in classroom contexts: The effects of incentives, reflection, and explanatory style. Metacognition \& Learning, 3, 101-121.

Horng, J.-S., Liu, C.-H., Chou, S.-F., \& Tsai, C.-Y. (2013). Creativity as a critical criterion for future restaurant space design: Developing a novel model with DEMATEL application. International Journal of Hospitality Management, 33, 96105.

Jing, F. F., \& Avery, G. C. (2008). Missing Links in Understanding the Relationship between Leadership and Organizational Performance. International Business \& Economics Research Journal, 7(5), 67-78. https://doi.org/10.1016/j.ijhm.2012.06.007

Johnson, H. (1983). The search for gain in markets and firms: a review of the historical emergence of management accounting systems. Accounting, Organizations and Society, 2(3), 139-184. https://doi.org/10.1016/0361-3682(83)90021-1

Jarvis, P., Holford, J., \& Griffin, C. (2006). The Theory and Practice of Learning. London and Strling: Kagob Page Ltd.

Jaeggi, S. M., Buschkuehl, M., Jonides, J., \& Perrig, W. J. (2008). Improving fluid intelligence with training on working memory. Proceedings of the National Academy of Sciences of the United States of America, 105, 6829-6833.

Kraiger, K. (2003). Perspectives on training and development. John Wiley \& Sons, Inc. https://doi.org/10.1002/0471264385.wei1208

Kanji , G., \& Sá, P. (2007). Performance measurement and business excellence: the reinforcing link for the public sector. Total Quality Management \& Business Excellence, 18(1-2), 49-56. https://doi.org/10.1080/14783360601043096

Kristensen, K., \& Westlund, A. H. (2004). Accountable business performance measurement for sustainable business excellence. Total Quality Management, 15((5-6)), 629-643. https://doi.org/10.1080/14783360410001680116

Kaplan, R. S., \& Norton, D. P. (1996). Strategy Map: converting intangible assets into tangible outcomes. Boston, US: Harvard Business School Publishing Corporation.

Lloyd, C. M., \& Modlin, E. L. (2012). Coaching as a key component in teachers' professional development: Improving classroom practices in Head Start settings. OPRE Report 2012-4, Washington, DC: Office of Planning, Research and Evaluation, Administration for Children 
and Families, U.S. Department of Health and Human Services.http://www.acf.hhs.gov/sites/default/files/opre/coaching_key.pdf

MILLER, R. G., JR. (1966). Simultaneous statistical inference. New York: McGraw-Hill.

Morgan, P. L., Patrick, J., Waldron, S. M., King, S. L., \& Patrick, T. (2009). Improving memory after interruption: Exploiting soft constraints and manipulating information access cost. Journal of Experimental Psychology: Applied, 15(4), 291-306. https://doi.org/10.1037/a0018008

Morgan,P. L., Patrick,J., \& Tiley,L.(2013).Improvingtheeffectiveness of an interruption lag by inducing a memory-based strategy. Acta Psychologica, 142(1), 87-95. https://doi.org/10.1016/j.actpsy.2012.09.003

McClelland, D. C. (1973). Testing for competence rather than for "intelligence." American Psychologist, 28(1), 1-14. https://doi.org/10.1037/h0034092

Menaker, E., Coleman, S., Collins, J., \&Murawski, M. (2006). Harnessing Experiential Learning Theory to achieve Warfighting Excellence. Paper presented at the Interservice/Industry Training, Simulation \& Education Conference, Orlando, FL.

Moullin, M. (2007). Performance measurement definitions: Linking performance measurement and organisational excellence. International Journal of Health Care Quality Assurance, 20(3), 181-183. https://doi.org/10.1108/09526860710743327

Neely, A. (1999). The performance management revolution: why now and what next. International Journal of Operations \& Production Management, 19(2), 205-228. https://doi.org/10.1108/01443579910247437

Neely, A., Gregory, M., \& Platts, K. (2005). Performance measurement system design:a literature review and research agenda. International Journal of Operations \& Production Management, 25(12), 1228-63.

Pongatichat, P., \& Johnston, R. (2008). Exploring strategy-misaligned performance measurement. International Journal of Productivity and Performance Management, 57(3), 207-22. https://doi.org/10.1108/17410400810857220

Pena, I., \&Villasalero, M. (2010). Business strategy, human resources system, and organizational performance in the Spanish banking industry. International Journal of Human Resource Management, 21, 2864-2888. https://doi.org/10.1080/09585192.2010.528670

Prince, C. W., \& Salas, E. (1993). Training and research for teamwork in the military aircrew. In E. Wiener, B. Kanki, \& R. Helmreich (Eds.). Cockpit resource management (337-366). San Diego. CA: Academic Press.Russ-Eft et al., 2010

Richey, R. (2000). The Legacy of Robert M. Gagne. New York: ERIC Clearinghouse on Information and Technology.

Rasmussen, R.V. (1982). Team training: A behavior modification approach. Group and Organization Studies, pre-1986, March, 51-66. https://doi.org/10.1177/105960118200700105 


\section{Macrothink}

Journal of Management Research

ISSN 1941-899X 2018, Vol. 10, No. 3

Riley, J. M., Endsley, M. R., Bolstad, C. A., \& Cuevas, H. M. (2006). Collaborative planning and situation awareness in army command and control. Ergonomics, 49, 1139-1153. https://doi.org/10.1080/00140130600612614

Shrivastava, P. (1983). A Typology of Organizational Learning Systems. Journal of Management Studies, 20(1), 7-28. https://doi.org/10.1111/j.1467-6486.1983.tb00195.x

Tichon, J. (2007). Training cognitive skills in virtual reality: Measuring performance. Cyber Psychology \& Behavior, 10(2), 286-289. https://doi.org/10.1089/cpb.2006.9957

Thomas, K. W. (2000). Intrinsic motivation at work: Building energy and commitment. San Francisco: Berrett-Koehler Publisher, Inc

Tannenbaum, S. I., \& Yukl, G. (1992). Training and development in work organizations. Annual Review of Psychology, 399-441. https://doi.org/10.1146/annurev.ps.43.020192.002151

Tanenbaum, D. M., Wang, Y., Williams, S. P., \& Sigler, P. B. (1998). Proc. Natl Academic Science, USA, 95, 5998-6003. https://doi.org/10.1073/pnas.95.11.5998

Taylor, P. J., Driscoll, M. P., \& Binning, J. F. (1998). A new integrated framework for training needs analysis. Human Resource Management Journal, 8(2), 29-50.

Ubeda-Garcia, Marco-Lajara, Sabater-Sempere and Garcia-Lillo (2013).

Virany, B., Tushman, M.L. and Romanelli, E. (1992). Executive succession and organization outcomes in turbulent environments: an organization learning approach. Organization Science, 3(4), 72-91. https://doi.org/10.1287/orsc.3.1.72

Vollmeyer, R., Burns, B. D., \& Holyoak, K. J. (1996). Theimpactofgoal specificity on strategy use and the acquisition of problem structure. Cognitive Science, 20, 75-100. https://doi.org/10.1207/s15516709cog2001_3

WIKE, E. L. (1971). Data analysis. New York: AldineAtherton.

Zikmund, G. W. (2003). Business Research Methods. Oklahoma: South-Western. 